Int. J. Dev. Biol. 49: 151-159 (2005)

doi: $10.1387 / \mathrm{ijdb} .041940 \mathrm{cr}$

\title{
The instability of the neural crest phenotypes: Schwann cells can differentiate into myofibroblasts
}

\author{
CARLA REAL, CORINNE GLAVIEUX-PARDANAUD, PIERRE VAIGOT, NICOLE LE DOUARIN \\ and ELISABETH DUPIN* \\ Laboratoire d'Embryologie Cellulaire et Moléculaire, CNRS UMR 7128, Nogent-sur-Marne, France
}

\begin{abstract}
In the vertebrate embryo, the neural crest cells (NCCs) that migrate out from the neural primordium yield multiple phenotypes, including melanocytes, peripheral neurones and glia and, in the head, cartilage, bone, connective cells and myofibroblasts / vascular smooth muscle cells (SMCs). The differentiation of pluripotent NCCs is mainly directed by local growth factors. Even at postmigratory stages, NC-derived cells exhibit some fate plasticity. Thus, we reported earlier that pigment cells and Schwann cells are able in vitro to interconvert in the presence of endothelin 3 (ET3). Here, we further investigated the capacity of Schwann cells to reprogram their phenotype. We show that purified quail Schwann cells in dissociated cultures produce $\alpha$ smooth muscle actin ( $\alpha$ SMA)-expressing myofibroblasts through the generation of a pluripotent progeny. This transdifferentiation took place independently of $E T 3$, but was promoted by transforming growth factor $\beta 1$ (TGF $\beta 1$ ). Moreover, when implanted into chick embryos, the Schwann cells were found to contribute with host cephalic NCCs to perivascular SMCs. These data provided the first evidence for the acquisition of an NC-derived mesenchymal fate by Schwann cells and further demonstrate that the differentiation state of NC-derived cells is unstable and capable of reprogramming. The high plasticity of Schwann cells evidenced here also suggests that, as in the CNS, glial cells of the PNS may function as NC stem cells in particular circumstances such as repair.
\end{abstract}

KEY WORDS: transdifferentiation, quail embryo, in vitro culture, transplantation, pluripotency

\section{Introduction}

During vertebrate embryogenesis, a number of cell types originates from a unique transitory structure, the NC. NCCs arise from the dorsal aspect of the neural primordium, undergo extensive migration as they proliferate and then differentiate in various organs and tissues (for references see, (Le Douarin, 1982, Le Douarin and Kalcheim, 1999). These cells give rise to skin melanocytes, some endocrine cells and the neural cells of the peripheral nervous system (PNS), including sensory, autonomic and enteric neurones and associated glial cells, as well as Schwann cells lining the peripheral nerves. In addition, the cranial and cervical NCCs yield several mesenchymal cell types (the so-called «mesectoderm»), which form most of the head dermis, cartilages and bones in the skull and facial skeleton (Couly et al., 1993, Le Lievre and Le Douarin, 1975). The cephalic NCCs also provide forebrain meninges, connective tissue cells in glands and muscles, the cardiac outflow tract as well as the myofibroblasts/SMCs that are associated with the vessels derived from the aortic arches and those irrigating the face and forebrain (Etchevers et al., 1999, Etchevers et al., 2001, Kirby and Waldo, 1995, Le Lievre and Le Douarin, 1975).

How these diverse NC-derived phenotypes are specified early and maintained later in the differentiated tissues, begins to be understood. The final phenotype adopted by NCCs depends mainly on local cues encountered by the cells during and at the end of their journey (reviewed in (Le Douarin and Dupin, 2003). Single cell studies, essentially carried out in vitro, have revealed that migratory NCCs include highly pluripotent as well as oligopotent (i.e., with a more limited developmental potential) progenitors and

Abbreviations used in this paper: CNS, central nervous system; d, culture day; E, embryonic day; ET1, endothelin 1;ET3, endothelin 3; ETRB, endothelin receptor B; NC, neural crest; NCCs, neural crest cells; NF, neurofilament; PNS, peripheral nervous system; $\alpha$ SMA, $\alpha$ smooth muscle actin; SMCs, smooth muscle cells; TGF $\beta$, transforming growth factor beta; $\mathrm{TH}$, tyrosine hydroxylase. 
fate-restricted precursors (Baroffio et al., 1988, Baroffio et al., 1991, Dupin et al., 1990, Sieber-Blum, 1991, Trentin et al., 2004). Some of the pluripotent and bipotent progenitors in the early NC are stem cells endowed with self-renewal capacity (Stemple and Anderson, 1992, Trentin et al., 2004).

At postmigratory stages, resident pluripotent stem cells were identified in the PNS (in nerves, dorsal root ganglia and gut) (Bixby et al., 2002, Iwashita et al., 2003, Kruger et al., 2002, Morrison et al., 1999). These in vitro findings confirm and further document a notion previously revealed by in vivo transplantations of quail PNS ganglia from quail into the NCC migration pathway of chick embryos at embryonic day 2 (E2) (for a review (Le Douarin and Kalcheim, 1999). Therefore, a certain degree of differentiation plasticity and regeneration capacities characterize the NC-derived cells long after PNS organogenesis is completed.

Besides the possible recruitment and differentiation of resting stem cells, another way to replenish organs is by converting already differentiated cells of one type to a different functional phenotype. Such «transdifferentiation» has been described long ago in vertebrates. One of the classical examples is the regeneration of the amphibian urodele tail, which proceeds by cell de-differentiation into blastemal cells capable to re-differentiate along various lineages (for references, (Brockes and Kumar, 2002). In higher vertebrates, conversion between cell types that develop in close relationship can occur, such as in the chick eye, between cells of the retinal pigmented epithelium, the neural retina and the lens (Eguchi and Okada, 1973, Okada, 1991). Otherwise, although rare in mammals, phenotype switch can be induced in vitro by growth factors, chemicals or by manipulating gene expression, as recently documented for myotubes (McGann et al., 2001, Odelberg et al., 2000).

In the quail NC, we have described recently two examples of phenotype conversion. Pigment cells and glial Schwann cells in vitro can convert into each others when exposed to the mitogenic signal of ET3, generating an intermediate cell type which express markers specific for both lineages (Dupin et al., 2000, Dupin et al., 2003). The Schwann cell and pigment cell progeny could also recapitulate the bipotentiality of their immediate common ancestor, the glialmelanocytic (GM) progenitor, previously identified in clonal cultures of migrating NCCs (Lahav et al., 1998). These data thus have suggested that differentiation of NCCs can be reversed, resulting eventually in phenotype conversion between NC lineages. To further investigate this possibility, we have examined here whether the isolated Schwann cells are able to switch to alternative NC phenotypes, in addition to the melanocytic phenotype. We have particularly focused our attention on the so-called "myofibroblasts», characterized by the expression of $\alpha \mathrm{SMA}$ and which correspond to muscle cells of NC origin associated in vivo with the blood vessels in the cephalic region. The present study shows that myofibroblasts arise from the Schwann cells in vitro independently of ET3. In addition, we find that this phenotype switch can also occur in vivo, since Schwann cells grafted into chick embryos yield vascular SMCs. This work suggests that NC-derived cell types may retain (or recover) the potential to differentiate along other NC lineages and it further supports the instability of NC phenotypes.

\section{Results}

\section{Isolated Schwann cells generate myofibroblasts in vitro}

The Schwann cells from E10.5 quails were immunopurified by FACS using the monoclonal antibody (Mab) against the Schwann cell myelin protein (SMP) (Dulac et al., 1988, Dulac et al., 1992) and grown in mass cultures in control or in ET3-supplemented medium as described (Dupin et al., 2003). The cultures were then analysed, at different time points, using several NC lineagespecific markers: SMP and P0 protein for Schwann cells, $\alpha$ SMA for myofibroblastic cells and neurofilament (NF) proteins and tyrosine hydroxylase (TH), to identify neurones and adrenergic cells, respectively.

In control cultures (withoutET3 supplementation) after overnight
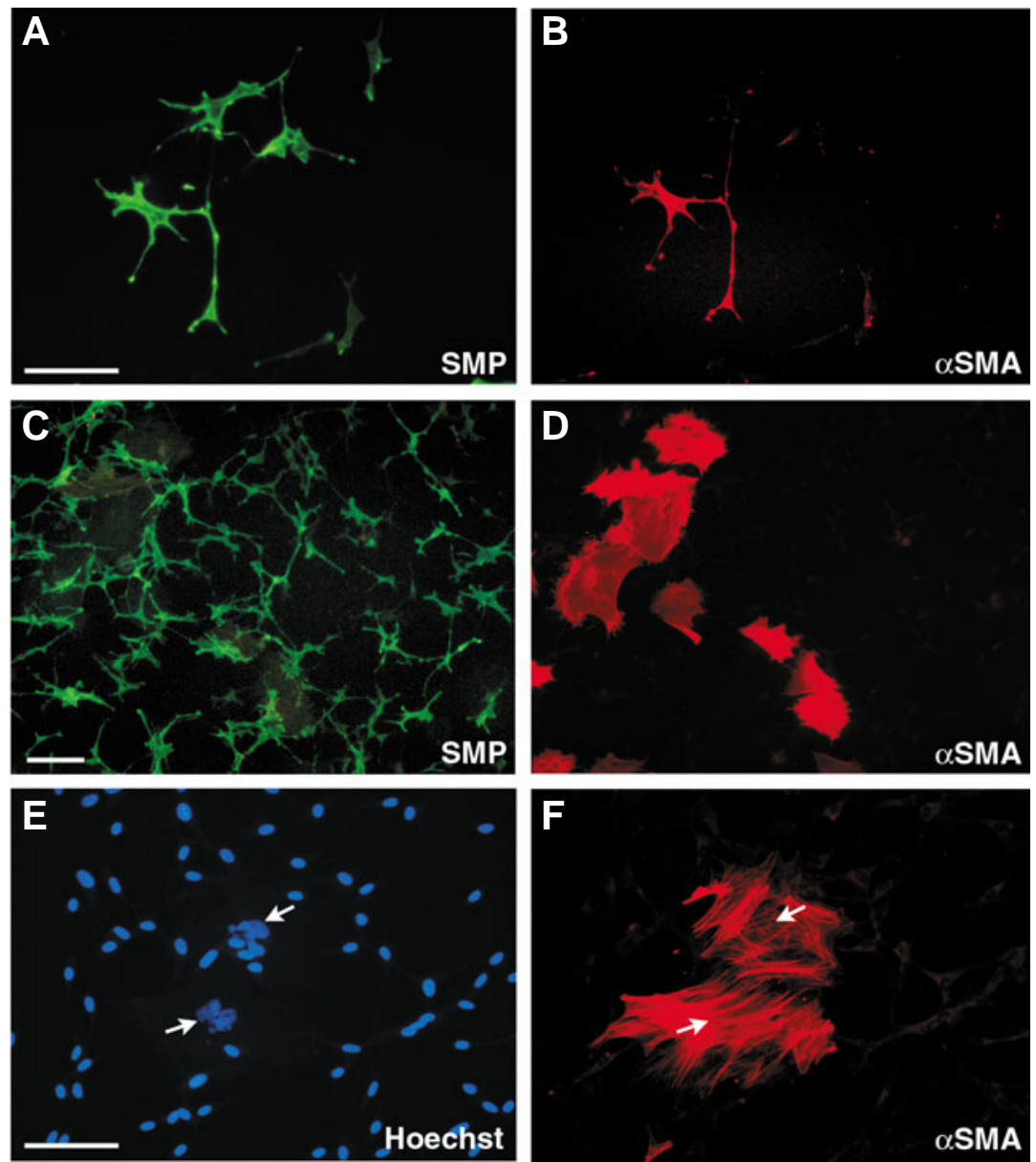

Fig.1. Expression of $\alpha$ SMA and SMP in Schwann cell control cultures. Expression of SMP and $\alpha S M A$, in the same optic field, at $d 3(\mathbf{A}, \mathbf{B})$ and $d 7(\mathbf{C}-\mathbf{F})$. Notice in $(F)$ that at $d 7$, the $\alpha S M A$ protein is assembled in filaments. Nuclei visualization by Hoechst staining (E) and expression of $\alpha S M A(\mathbf{F})$ at $d 7$. The $\alpha S M A$-expressing cells exhibit a much larger nucleus than the other cultured cells (arrows). All detected by immunofluorescence. Bar, $100 \mu \mathrm{m}$ in $A, B$ and $E, F ; 300 \mu \mathrm{m}$ in $C, D$. 
incubation (culture day 1-d1), virtually all cells expressed the glial proteins SMP and P0 as well as p75 NGF low-affinity receptor (not shown); neither $\alpha$ SMA nor neuronal markers were detected, thus supporting the initial glial identity of the plated cells. Later on, the glial markers were progressively down regulated by a subpopulation of the cultured cells. At d3 and concomitantly with the extinction of glial markers, $\alpha S M A-$ expressing cells emerged. At this time point, the majority of the $\alpha \mathrm{SMA}^{+}$cells still expressed SMP and maintained the same elongated morphology as $\mathrm{SMP}^{+}\left(\alpha \mathrm{SMA}^{-}\right)$glial cells (Fig. 1A, B). At d7, most of the $\alpha \mathrm{SMA}^{+}$cells had lost the expression of SMP and exhibited a large and flattened morphology as well as a high level of $\alpha$ SMA immunoreactivity in cytoplasmic filaments (Fig. $1 C, D)$. These cells also possessed a much larger nucleus than $\mathrm{SMP}^{+}$cells (Fig. 1E, F). Relying on all these features, we designated those $\alpha \mathrm{SMA}^{+}$cells "myofibroblasts".

In ET3-treated cultures, the transition from SMP+ Schwann cells to myofibroblasts occurred similarly to non-treated cultures. However, the presence of ET3 increased the total number of cells, but maintained the proportion of myofibroblasts (about $0.1 \%$ of total cells). In both culture conditions at $d 7$, neither neurones nor melanoblasts/melanocytes were detected. However, melanocytic cells differentiated in cultures maintained in the presence of ET3 for a longer culture time (see below), as described previously (Dupin et al., 2003).

These data therefore show that Schwann cells developing in culture de-differentiate and are able to generate myofibroblasts in their progeny, independently of the presence of ET3. The finding of an intermediate phenotypic state, in which cells coexpress glial (SMP) and myofibroblastic ( $\alpha$ SMA) proteins, suggests that the transition from glial to myofibroblastic cells is progressive.

\section{Marker expression in the transition of Schwann cells to myofibroblasts}

In order to further characterise the Schwann cell-myofibroblast phenotype transition, we have verified the expression, by differentiating $\alpha \mathrm{SMA}^{+}$cells, of additional markers, expressed by both NCCs and differentiated Schwann cells, that is, the transcription factor gene Sox10 (Cheng et al., 2000) and the HNK1 surface carbohydrate epitope (Abo and Balch, 1981, Tucker et al., 1984). Moreover, we examined Slug expression in the cultures. In vivo, this transcription factor is required by early avian NCCs for emigration from the dorsal neural tube (Nieto et al., 1994) and is re-expressed later by differentiated vascular SMCs (Marin and Nieto, 2004).

These experiments were performed in control and ET3supplemented media, which gave similar results. In d1-cultures, virtually all cells expressed, together with SMP, HNK1, Sox10 and the gene encoding the endothelin receptor $B$ (ETRB) (not shown). However, at d3, some cultured cells, including part of the $\alpha \mathrm{SMA}^{+}$cells, had lost these markers. The $\alpha \mathrm{SMA}^{+}$cells were thus heterogeneous; some were negative for HNK1 immunoreactivity (Fig. 2A, B) and others no longer expressed Sox 10 transcripts (Fig. 2C, D). At d7, the $\alpha \mathrm{SMA}^{+}$myofibroblasts had completely extinguished both HNK1 (Fig. 2E, F) and Sox10 (Fig. 2G, H). However, these two markers were occasionally present in a minor fraction of the $\alpha \mathrm{SMA}^{+}$cells that were still small and elongated as d3-cultured cells are (Fig. 2G, H-arrowheads).
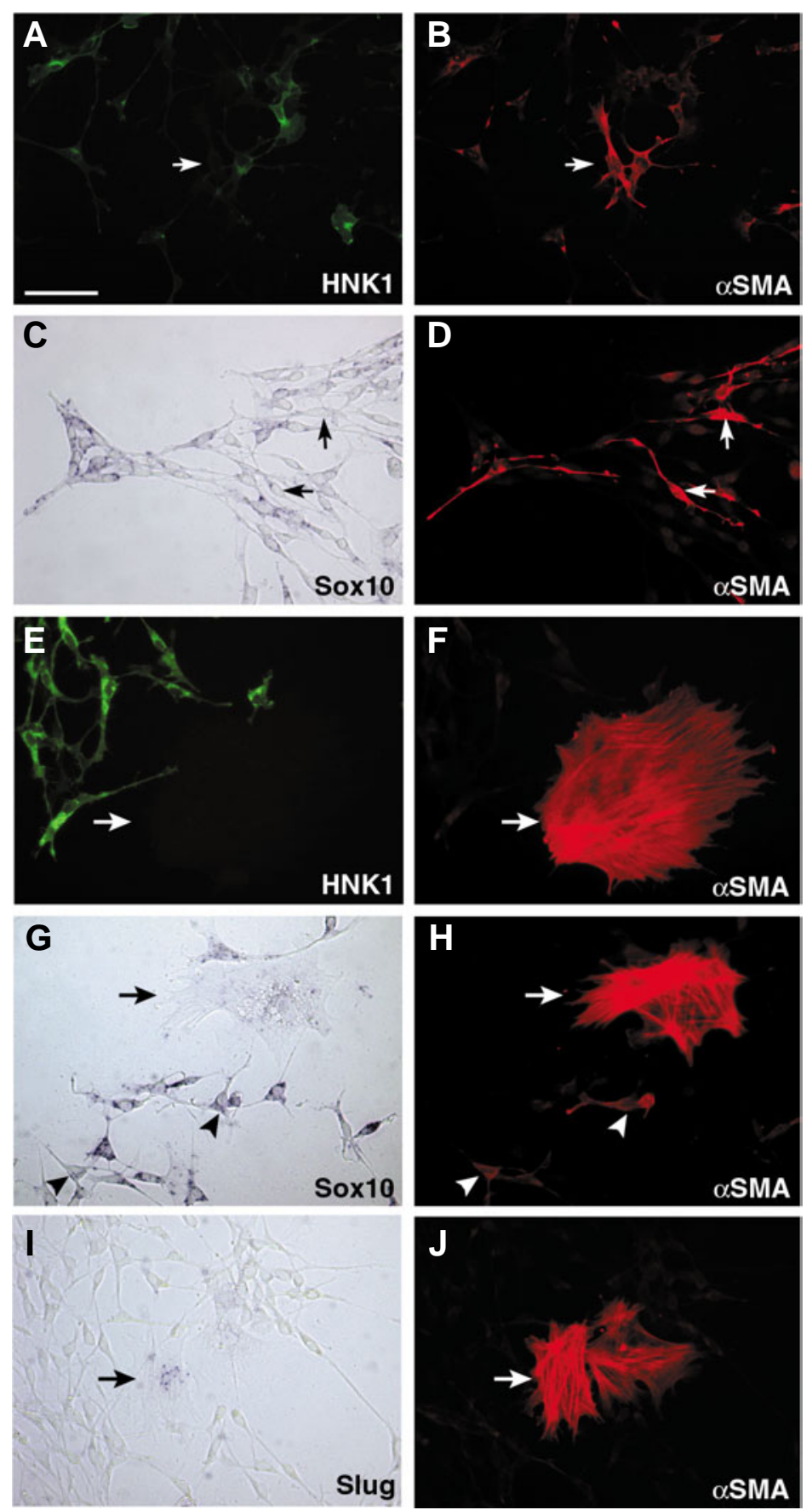

Fig. 2. Expression of HNK1, Sox 10 and Slug by $\alpha$ SMA-positive cells in $\mathbf{d} 3$ and d 7 -Schwann cell cultures. In d3-Schwann cell cultures (A-D): Immunofluorescence with HNK1 (A) and $\alpha S M A(\mathbf{B})$, which is the same field as (A) and detection of both Sox10 mRNA (C) (bright field) and aSMA (D), which is the same field as (C). A subset of $\alpha S M A^{+}$cells has lost the HNK1 epitope (arrow in $A, B$ ) and does not express Sox10 (arrows in C,D). In d7-Schwann cell cultures (E-J): double labelling with $\alpha S M A$ and HNK 1 (E,F), $\alpha S M A$ and Sox $10(\mathbf{G}, \mathbf{H})$ and $\alpha S M A$ and Slug $(\mathbf{I}, \mathbf{J})$. $(E, F),(G, H)$ and $(I, J)$, same optic fields. The $\alpha S M A^{+}$large fibroblastic cells are HNK1-negative (arrow in E,F) and do not express Sox10 (arrow in $G, H$ ). Sox 10 transcripts are detected in small elongated $\alpha S M A^{+}$cells (arrowheads in $G, H$ ). Some $\alpha S M A^{+}$fibroblastic cells express Slug (arrow in I,J). Bar, $100 \mu \mathrm{m}$. 

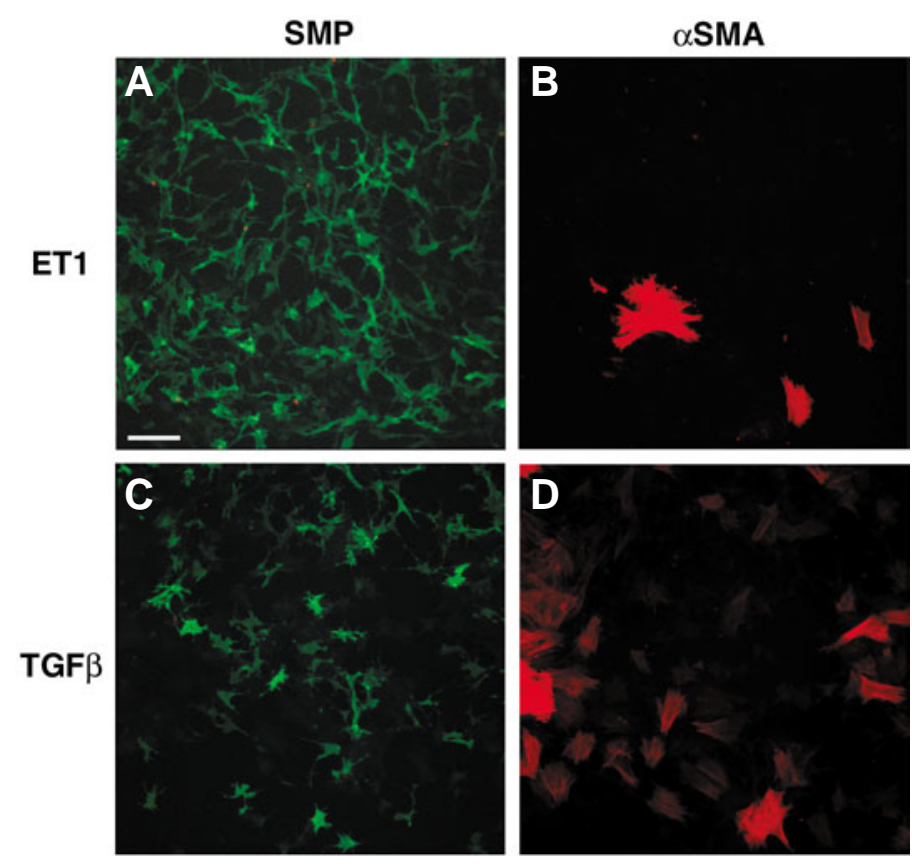

Fig. 3. Expression of SMP and $\alpha \mathrm{SMA}$ in d7 Schwann cell cultures treated with ET1 (A,B) and TGF $\boldsymbol{\beta} 1$ (C,D). SMP and $\alpha S M A$ expression was detected by immunofluorescence. $(A, B)$ and $(C, D)$ same optic field. Bar, $300 \mu \mathrm{m}$.

S/ug transcripts were never detected in d3-cultures. By contrast, the expression of this gene was identified at $\mathrm{d} 7$ and exclusively in some myofibroblasts (Fig.2I, J).

Therefore, the Schwann cells which start synthesising $\alpha$ SMA loose progressively the expression of Sox10 and HNK1 from d3 onward, although this is not the case for the expression of SMP. Later in the transition from glial to myofibroblastic phenotypes, all the Schwann cell markers tested here, including SMP, are extinguished in differentiated myofibroblasts. In addition, some of these cells activate the S/ug transcription factor gene.

\section{Effect of growth factors on myofibroblast production by cultured Schwann cells}

The present results have shown that differentiation of myofibroblasts from Schwann cells did not require the presence of ET3 in the culture medium. We therefore tested whether the addition of other factors, implicated in the development of perivascular smooth muscle cells in vivo and in vitro, could stimulate the generation of myofibroblasts by cultured Schwann cells. Cultures prepared as above were grown in control medium further supplemented with either TGF $\beta 1$ or ET1. They were analysed at $\mathrm{d} 3$ and $\mathrm{d} 7 \mathrm{for}$ the presence of glial and myofibroblastic cells and compared with control and ET3-treated cultures at the same time points.

Treatment with ET1 increased the number of $\mathrm{SMP}^{+}$glial cells and both types of $\alpha \mathrm{SMA}^{+}$cells (co-expressing or not SMP), as compared to control medium (Fig. 3A, B). Such overall growth stimulation by ET1 in Schwann cell cultures was thus similar to the effect of ET3 (Dupin et al., 2003).

Exposure to TGF $\beta 1$ did not stimulate Schwann cell growth as compared to control cultures. However, this factor strongly enhanced the morphological and phenotypic differentiation of myofibroblastic cells. As soon as d3, most of the $\alpha \mathrm{SMA}^{+}$cells had differentiated to large and flattened SMP- cells, while smaller cells expressing both $\alpha$ SMA and SMP were rarely found. Moreover, when these cultures were exposed to TGF $\beta 1$ until $d 7$, the percentage of myofibroblasts increased significantly as compared to control and ET3-treated cultures ( $4 \%$ versus $0.1 \%$ ) (Fig. 3C, D).

Therefore, among the growth factors tested here, TGF $\beta 1$ has the unique ability to promote differentiation of the myofibroblasts arising from cultured Schwann cells. In the present conditions (i.e., in serum and embryo extract-containing medium), addition of ET1 does not alter the emergence of the myofibroblast phenotype.

\section{Myofibroblast differentiation potential by Schwann cell clonal progeny}

To analyse the developmental potential of the Schwann cells that convert into myofibroblasts, we performed clonal cultures of $\mathrm{SMP}^{+}$nerve cells and compared the cellular composition of the clones obtained in the absence and presence of ET3. This factor, although not necessary for the generation of myofibroblasts in mass cultures, was previously shown to promote clone survival and melanocyte outcome in long-term single Schwann cell cultures (Dupin et al., 2003).

Clones were thus maintained until d17 and analyzed for cell survival, growth and presence of glial, melanocytic and myofibroblastic cells. Table 1 shows the detailed distribution of the different types of clones. In control medium, the majority of the clones generated by Schwann cells contained both glial cells and myofibroblasts (GF clones). The others were composed only of glial cells ( $G$ clones), myofibroblasts ( $F$ clones) or lineage markernegative cells (unidentified, $U$ clones). In presence of ET3, besides clones of the G, F, GF and U types already identified in control cultures, two additional clone types were recorded which contained melanocytic cells, i.e., GM clones (with both glial and melanocytic cells) and GMF clones (with glial, melanocytic and myofibroblastic cells). Although it allowed generation of melanocyte-containing progeny, the treatment with ET3 did not significantly modify the overall proportion of the clones containing myofibroblasts ( $37.8 \%$ versus $60.5 \%$ in controls; $P=0.5$ ).

TABLE 1

\section{PHENOTYPIC ANALYSIS OF CLONAL CULTURES DERIVED FROM SCHWANN CELLS}

\begin{tabular}{ccrc} 
Clone types & control & \multicolumn{1}{c}{ ET3 } & P \\
\hline G & $13(30.2 \%)$ & $17(32.1 \%)$ & $n s$ \\
F & $3(7 \%)$ & $11(20.7 \%)$ & $n s$ \\
GF & $23(53.5 \%)$ & $3(5.7 \%)$ & $<0.05$ \\
GM & 0 & $11(20.7 \%)$ & - \\
GMF & 0 & $6(11.4 \%)$ & - \\
U & $4(9.3 \%)$ & $5(9.4 \%)$ & $n s$ \\
\hline
\end{tabular}

Purified SMP+ Schwann cells plated individually and grown in control and ET3supplemented medium, gave rise to similar numbers of $\mathrm{d} 1$-colonies $(66 \%$ and $69 \%$, respectively from 210 plated cells in each medium). At d17, the clones were analyzed for cell phenotypes using lineage-specific markers. The absence or presence of SMP ${ }^{+}$ glial cells $(G), M^{2}$ MeM $^{+}$melanocytic cells $(M)$ and $\alpha$ SMA $^{+}$myofibroblastic cells $(F)$, led to classify the clones in 6 different categories. Those referred as to unidentified clones (U) contained exclusively marker-negative (SMP-, MelEM- $\left.{ }^{-}, \mathrm{SMA}^{-}\right)$cells. The number (and percent of total clones) is given for each clone type. $\mathrm{P}$ values from statistical analysis of control and ET3-treated cultures; ns, not significant. 

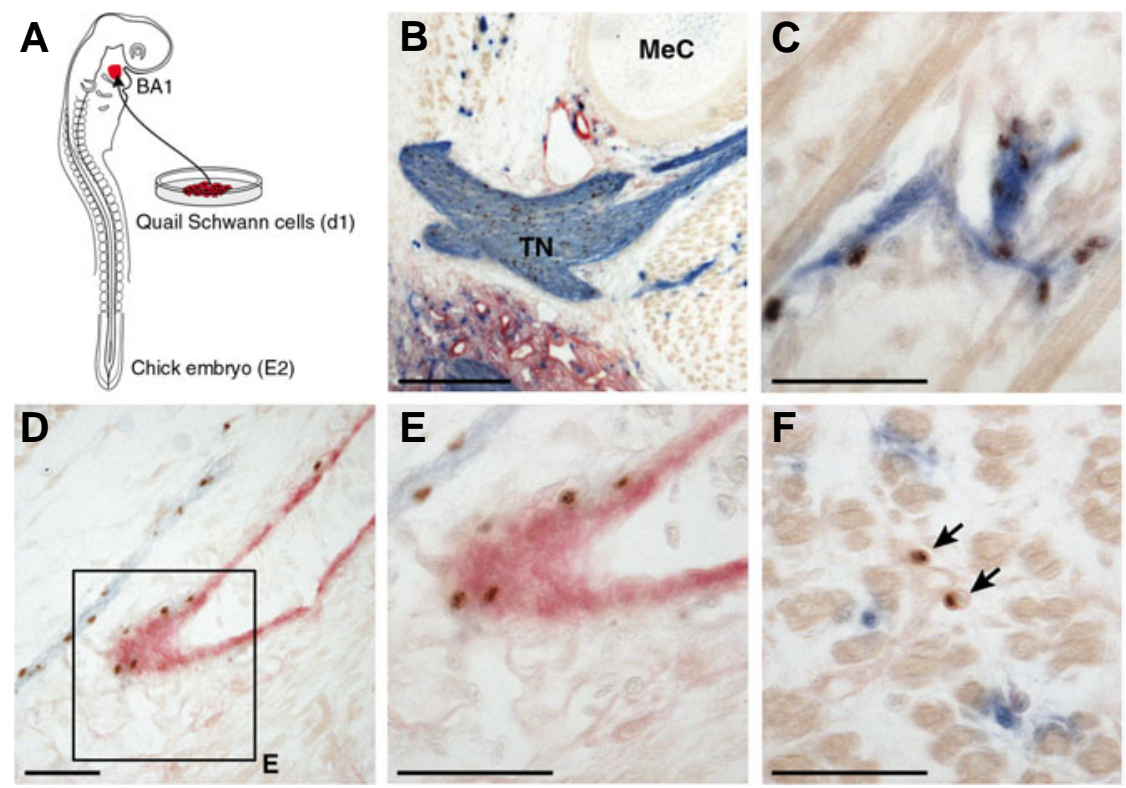

Fig. 4. Fate of Schwann cells when back-transplanted into chick embryos. Unilateral implantation of d1-cultured Schwann cells in the first branchial arch of a chick embryo (A). At E9, histological sections of the host mandible were stained with QCPN Mab (in brown), HNK1 Mab (in blue) and $\alpha S M A M a b$ (in red). The QCPN-positive cells had integrated HNK $1^{+}$ trigeminal nerve, TN in (B) and nerve fibers innervating the depressor facial muscle (C). They also homed to the vascular smooth muscle layer where they express $\alpha S M A$ (D) which is amplified in (E). Other engrafted cells which expressed neither SMP nor $\alpha$ SMA, were dispersed in facial muscles; see arrows in (F). Bar, $300 \mu \mathrm{m}$ in (B) and $50 \mu \mathrm{m}$ in (C-F). Abbreviations: BA1, first branchial arch; MeC, Meckel's cartilage.

Taken together, these data further argue for the ability of embryonic Schwann cells in vitro to reprogram their phenotype along NC-derived melanocyte and myofibroblast lineages. In most cases, myofibroblastic cells arise from bipotent (GF) and pluripotent (GMF) progeny, thus indicating that conversion of Schwann cells to myofibroblasts likely involves reversal to a pluripotent state.

\section{Transplanted Schwann cells generate perivascular SMCs in vivo}

In order to investigate whether Schwann cells isolated from embryonic sciatic nerves could give rise to myofibroblasts in vivo as they did in culture, we examined if these cells would integrate into the smooth muscle layer of developing blood vessels in younger embryos. For this purpose, Schwann cells issued from d1-control cultures were implanted unilaterally into the first branchial arch (BA1) of E2-chick embryos, that is, at the time when myofibroblast precursors, derived from the host cephalic NC, colonise the head vascular network (Etchevers et al., 2001) (Fig. 4A). The host embryos were re-incubated and analysed at E9. Cells derived from the implant were then identified in histological sections by using the quail-specific QCPN Mab. Simultaneously, the vascular SMC phenotype was revealed using $\alpha$ SMA and the PNS component cells using HNK1. The engrafted cells were found in the BA1-derived host mandibular process 7 days postgrafting (Fig. 4 B-F). Some of these cells lined the host cranial peripheral nerves, including the trigeminal nerve and the fibres that innervate the facial muscles (Fig. 4B, C). In these locations, the graft-derived cells exhibited HNK1 immunoreactivity, indicative of their glial identity. Another large subset of the implanted cells had homed to host blood vessels and integrated the periendothelial smooth muscle layer, as shown by co-expression of QCPN and $\alpha$ SMA (Fig. 4D, E). The vascular smooth muscle layer was also colonised by HNK $1^{+} \alpha \mathrm{SMA}$ - quail cells, which very likely represent graft-derived Schwann cells that accompany the host terminal autonomic innervation of the vascular mural cells (not shown). In addition, other quail cells, located in the vicinity of blood vessels or within facial muscles, did not express either HNK1 or $\alpha$ SMA (Fig. 4F).

Therefore, Schwann cells isolated from embryonic nerves and back-transplanted into a younger host embryo are able to re-populate host peripheral nerves, maintaining their initial Schwann cell phenotype. More importantly, as in culture, they also generate myofibroblasts expressing the $\alpha$ SMA protein in vivo. Furthermore, these graftderived myofibroblasts are capable to contribute to normal development of the muscular wall of the developing host blood vessels.

\section{Discussion}

We have previously shown that Schwann cells isolated from embryonic nerves are capable of changing their lineage program and generate pigment cells in long-term cultures supplemented with ET3 (Dupin et al., 2003). Here we describe that, in addition to melanocytes, these cells give rise to another NC-derived phenotype, the myofibroblasts, which are obtained earlier in culture than melanocytes and independently of the cytokine ET3. Moreover, by using transplantation experiments, we show that the Schwann cells also generate myofibroblasts in vivo, which are recruited by blood vessel primordia to participate in the formation of the perivascular smooth muscle.

\section{Characterisation of the transition from Schwann cells to myofibroblasts/SMCs}

In this work, we have focused on the phenotype plasticity of Schwann cells that were isolated from quail sciatic nerves (as described in (Dupin et al., 2003), using the surface glycoprotein SMP (Dulac etal., 1988, Dulac et al., 1992, Dupin etal., 1990). The expression of SMP is detected from E5 in quail Schwann cells, when those have already contacted the nerve fiber (Dulac et al., 1988). The $\mathrm{SMP}^{+}$sorted cells from E10.5 quail nerves also express the myelin protein $\mathrm{PO}$ characteristic of Schwann cells (Bhattacharyya et al., 1991). In addition, they express the transcription factor Sox10 (Cheng et al., 2000) and the HNK1 epitope (Tucker et al., 1984). These markers are present in vivo in early NCCs and later in PNS cells, including Schwann cells, but are lost by mesenchymal and melanocytic NC derivatives. Here we identified the myofibroblasts by morphological criteria and expression of $\alpha \mathrm{SMA}$ and S/ug. The myofibroblasts, together with the pericytes and SMCs, are the components of the periendothelial muscular wall in maturing blood vessels. They have been shown to derive from NCCs in the cephalic region (Etchevers et al., 2001, Le Douarin 
and Kalcheim, 1999) and, in the other body regions, from the mesoderm or from the epicardium in the case of coronary vessels (for references, (Owens, 1995). The $\alpha$ SMA cytoskeletal protein is the early and widest used marker for myofibroblasts/SMCs differentiating either in vivo or in vitro. In particular, this marker led to the characterisation of SMCs derived from avian and mammalian NCCs (Ito and Sieber-Blum, 1991, Jain et al., 1998, Shah et al., 1996, Trentin et al., 2004, Youn et al., 2003). The transcription factor Slug, which is required for the emigration of the early NCCs (Nieto etal., 1994), has been shown recently to label avian vascular SMCs/pericytes (Marin and Nieto, 2004).

We report here that, when purified Schwann cells develop and divide in culture, they generate a subpopulation of myofibroblasts. By analysing the developmental potentials of individual Schwann cells in vitro, we show that, first, the ability to switch phenotype is independent of Schwann cell density. Moreover, we provide evidence that the differentiation of myofibroblasts from Schwann cells involves common progenitor cells for glial and myofibroblastic cell types. The multilineage myofibroblast-containing clones derived from Schwann cells also contained glia or both glia and melanocytes and therefore were of the GF or GMF types, which are similar to those previously obtained from trunk and cephalic quail NCC cultures (Trentin et al., 2004). This demonstrates that Schwann cells, or their immediate progeny, behave as pluripotent NC-like cells.

The analysis of the dynamics of SMP, HNK1, Sox 10 and $\alpha \mathrm{SMA}$ expression in the cultures, allows us to distinguish two phases during the generation of myofibroblasts from Schwann cells. The first, i.e. the induction phase, takes place between $\mathrm{d} 0$ and $\mathrm{d} 3$ and corresponds to the emergence of $\alpha \mathrm{SMA}$ expression. This phase is characterised by the production of multiple cell states, intermediate between the Schwann cell and myofibroblast phenotypes, where $\mathrm{SMP}^{+} \alpha \mathrm{SMA}^{+}$cells also express or not HNK1 and/or Sox10 and maintain the morphological features of the parental glial cells. In the subsequent differentiation phase, between d3 and d7, the $\alpha \mathrm{SMA}^{+}$ cells loose their glial (SMP, P0, HNK1 and Sox10) features and acquire SMC characteristics, as defined by fibroblastic morphology, filamentous $\alpha$ SMA and, in some cases, expression of S/ug.

The above data thus reveal that the Schwann cells (or their immediate progeny) are able to switch their initial phenotype and generate myofibroblasts, another NC-derived cell type. However, they do not allow to identify with certainty the myofibroblast progenitor in Schwann cell descendance. Either it is a SMP+ Schwann cell that can directly convert in a myofibroblast, or it is a multipotent precursor that needs first to be produced by Schwann cell de-differentiation. Our results argue for the first possibility, since no dedifferentiation state (particularly no downregulation of SMP) was found to precede the onset of $\alpha$ SMA expression. Among the growing number of studies showing transdifferentiation in vertebrates, only a few were able to unambiguously characterise a de-differentiation process, by using clonal analysis and available precursor-specific markers (Brockes and Kumar, 2002, Odelberg et al., 2000, Tsonis, 2004).

We have shown that Schwann cells can give rise to myofibroblasts/SMCs and melanocytes (Dupin et al., 2003 and the present work), revealing their high level of cell plasticity. In the central nervous system (CNS) of adult vertebrates, some glial cells were also identified as pluripotent precursor cells. Astrocytes and radial glial cells behave as neural stem cells, generating neurons and glial cells in vivo and in vitro (for references, Doetsch, 2004).
Moreover, the Müller glial cells of the retina can be recruited after injury to regenerate neurones (Fischer and Reh, 2001). Therefore, it is conceivable that, as in CNS, glial cells of the PNS may function as NC stem cells in particular circumstances such as repair.

\section{Influence of growth factors on phenotypic conversion of Schwann cells}

Attempting to determine whether the switch from Schwann cells to myofibroblasts is influenced by growth factors, we first found that the progression of Schwann cells along the myofibroblast differentiation pathway is independent of ET3 and ET1. The addition of these peptides did not significantly influence the generation of myofibroblastic cells in d7-Schwann cell cultures, although it stimulated the overall cell division. The ET1 peptide interacts with both ETRB and endothelin receptor A (ETRA) reviewed by (Masaki, 2004) and the disruption of ET1/ETRA pathway in mice induces malformations of the cephalic and cardiac NC derivatives, including the blood vessels (Clouthier et al., 1998, Kempf et al., 1998, Kurihara et al., 1994). Our results suggest that ET1, similarly to ET3, acts through ETRB, to enhance cell proliferation. Accordingly, in longer-term clonal cultures (d17), the presence of ET3 did not change the frequency of Schwann cells yielding myofibroblasts, as shown previously for the myofibroblastic precursors of the quail NC (Trentin et al., 2004). Instead, ET3 triggers the differentiation of melanocytes in Schwann cell and NCC cultures, as previously reported (Dupin et al., 2003). The present data therefore reveal that myofibroblasts and melanocytes can arise from the same GMF, initially derived from Schwann cells, in the presence of ET3.

We further show that, in contrast to ET3 and ET1, TGF $\beta 1$ is able to promote myofibroblast differentiation from isolated Schwann cells in culture. In vivo, this factor induces mesenchymal cell differentiation into pericytes/SMCs (Rossant and Howard, 2002) by increasing the activity of specific SMC genes, such as $\alpha S M A$ (reviewed in (Kumar and Owens, 2003). In addition, TGF $\beta 1$ favours the differentiation in vitro of SMCs from rat embryonic NC stem cells (Mann et al., 2004, Shah et al., 1996) and from a pluripotent mouse NC cell line (Chen and Lechleider, 2004, Jain et al., 1998). Here we found that TGF $\beta 1$ triggers premature differentiation of myofibroblasts in $\mathrm{d} 3$ cultures and increases the myofibroblast number at $\mathrm{d} 7$. Whether TGF $\beta 1$ favours the production of myofibroblasts in the induction and/or the differentiation phases, is presently unclear. One possibility is that TGF $\beta 1$ influences the decision to activate $\alpha$ SMA synthesis in the induction phase, resembling its instructive effect on the differentiation of myofibroblasts from NC stem cells (Shah et al., 1996).

It is noteworthy that all culture media tested here, including control medium, have permitted the emergence of myofibroblasts in the Schwann cell cultures. This might be due to the activation by the serum of potent transcriptional inducers of smooth muscle protein genes (including $\alpha S M A)$, like serum response factors (SRFs) (Kumar and Owens, 2003, Oettgen, 2001). Indeed, Schwann cells cultured in "low-serum medium" (containing 1\% foetal calf serum only) maintained their phenotype, did not divide and produced no $\alpha$ SMA-expressing cells (data not shown).

\section{Schwann cells can give rise to SMCs in vivo}

We also show that the same phenotypic switch, from Schwann cells to myofibroblasts, occurs in vivo. Moreover, when the SMP+ 
Schwann cell population is grafted into early chick embryos, the engrafted cells generate vascular SMCs that integrate the wall of the host cranial vessels. Another subset of graft-derived cells, which do not express glial or SMC markers and are located in striated muscles, may correspond to fibroblasts of the connective tissues, an alternative derivative of cephalic NCCs (see Le Douarin and Kalcheim, 1999). The signals, which promote homing of engrafted Schwann cells to the blood vessel wall and their conversion in vivo into vascular myofibroblasts, are still to be identified. It is however to be noted that, in the grafting experiments, none of the Schwann cell descendants contributed to the pigment cell lineage, although this occurs in vitro. One possibility to account for such failure to produce melanocytes in vivo may be that the post-grafting period (7days) is insufficient to trigger pigment cell differentiation from the Schwann cells, as in culture, the latter requires at least 13 days of exposure to ET3 (Dupin et al., 2003). Alternatively, the branchial arch environment could restrict the melanogenic potential of the grafted cells, as observed for NCCs (Ciment and Weston, 1985, Jacobs-Cohen et al., 2002).

An interesting characteristic of the vascular and the peripheral nervous systems is that blood vessels and nerve fibres develop in close relationship and share a number of signalling molecules, which influence the differentiation of their respective cell types and direct their growth (Bates et al., 2003, Carmeliet, 2003, Mukouyama et al., 2002). Taken all these informations together, we suggest that, in case of injury wherein both blood vessels and nearby nerves have been damaged, some Schwann cells, which become separated from the axon and escape nerve cues (Fawcett and Keynes, 1990), might be induced, under the influence of signals issued from the neighbouring blood vessels, to change their phenotype and eventually take part in the regenerating perivascular muscular wall.

In conclusion, the present in vitro and in vivo experiments have revealed the ability of Schwann cells, isolated from the sciatic nerve, to reprogram toward mesenchymal fates that consist of myofibroblasts/SMCs of the vascular system and connective tissue cells. The myofibroblasts, which in normal development derive from cephalic NCCs, arise here in cultures of Schwann cells of trunk origin. In fact, trunk NCCs possess a myofibroblastic cell potential, which is not expressed in vivo but which can be revealed by in vitro culture (Hagedorn et al., 1999, Morrison etal., 1999, Shah et al., 1996, Trentin et al., 2004) or by heterotopic grafting (Nakamura and Ayer-le Lievre, 1982). Therefore, it can be concluded that the embryonic Schwann cells are able, not only to recover a developmental pathway specific of their NC precursors (melanocytic differentiation), but also to recapitulate some mesenchymal potential, expressed in vivo by the cephalic NCCs.

\section{Materials and Methods}

\section{Cultures of purified quail Schwann cells}

Cultures were prepared essentially as described previously (Dupin et al., 2003). Briefly, sciatic nerves of $E 10.5$ quails were dissociated to single cells and labelled with the Mab against SMP, a glycoprotein expressed by Schwann cells in myelinated and unmyelinated avian peripheral nerves (Dulac et al., 1988, Dulac et al., 1992). The $\mathrm{SMP}^{+}$cells were purified by FACS and then transferred to mass cultures $\left(5 \times 10^{3}\right.$ cells per $20 \mu \mathrm{l}$ culture medium) or plated as single cells by micro-manipulation (Dupin et al., 2003). Cells were grown on rat tail collagen substratum (Biomedical Technologies Inc.) in "cloning medium" containing $10 \%$ fetal calf serum
(Dutscher), 2\% chick embryo extract and various hormones and growth factors as described (Dupin et al., 2000, Dupin and Le Douarin, 2003, Dupin et al., 2003, Lahav et al., 1998, Trentin et al., 2004). After overnight incubation, medium was added to the cultures and changed every 3 days thereafter.

When indicated, the culture medium was supplemented with $100 \mathrm{mM}$ human ET3 or ET1 (Sigma), or with human TGF $\beta 1$ ( $1 \mathrm{ng} / \mathrm{ml}$; R\&D Systems). All cultures were incubated at $37^{\circ} \mathrm{C}$ in a humidified $5 \% \mathrm{CO} 2$, $95 \%$ air atmosphere and maintained until $\mathrm{d} 3$ and $\mathrm{d} 7$, for mass cultures and until d17, for clonal cultures.

\section{Immunocytochemical analysis of the cultures}

The cell phenotypes in the cultures were identified using lineagespecific markers after fixation with $4 \%$ paraformaldehyde. Glial cells were immunostained with Mabs against SMP (Dulac et al., 1988, Dulac and Le Douarin, 1991, Dulac et al., 1992) or protein P0 (Bhattacharyya et al., 1991) (1E8 clone supplied by Developmental Studies Hybridoma Bank (DSHB); University of lowa, lowa City, IA) using "Tyramide Signal Amplification" (TSA fluorescence systems, PerkinElmer) (Dupin et al., 2003). Neurones and adrenergic cells were labelled using rabbit serum against 200 KD NF protein (Sigma) and anti-quail TH Mab (Fauquet and Ziller, 1989), respectively. Pigment cells were recognised by melanin granules and unpigmented melanocytes by staining with the melanoblast/ melanocyte early marker (MelEM) Mab (Nataf etal., 1993). Myofibroblastic cells were visualized by immunoreactivity for $\alpha$ SMA (1:400, 1 A4 clone; Sigma). When indicated, immunostaining with rabbit polyclonal anti-p75 low-affinity NGF receptor (1:200, Chemicon) and HNK1 Mab (Abo and Balch, 1981) (undiluted hybridoma supernatant) was also carried out.

Secondary antibodies were purchased from Southern Biotechnologies Associates. Detailed staining procedures are described elsewhere (Dupin et al., 2000, Dupin et al., 2003, Lahav et al., 1998, Trentin et al., 2004). Fluorescence was observed under an Olympus (Melville, NY) X70 inverted microscope.

The average percentage of myofibroblastic cells in the cultures was determined as the ratio between the number of $\alpha$ SMA-labelled cells and the total number of cell nuclei counted after staining with Hoeschst bisbenzimide (Trentin et al., 2004) in at least four microscopic fields.

Differences in colony numbers between ET3-treated and control clonal cultures were analysed by $X^{2}$ test (GraphPad InStat, San Diego) and considered to be statistically significant when $P<0.05$.

\section{In situ hybridisation}

Antisense RNA probes to chick transcription factor genes So 10 and S/ug (gifts from P. Scotting and M.A. Nieto, respectively) were generated according to Cheng etal. (2000) and Nieto' etal. (1994). In situ hybridisation on cell cultures was performed as described previously (Lahav et al., 1998). Briefly, the cultures were fixed with $4 \%$ formaldehyde, dehydrated and then kept at $-20^{\circ} \mathrm{C}$. After rehydration and pre-hybridisation steps, they were hybridised with digoxigenin-labelled probes. Hybrids were revealed using alkaline phosphatase (AP)-anti-digoxigenin Mab (Roche) and colour staining was developed in nitroblue tetrazolium and 5-bromo-4-chloro-3indolyl phosphate (Sigma) substrate. The stained cultures were then processed for immunofluescence labelling with HNK1 and $\alpha \mathrm{SMA}$ as described above.

\section{Transplantation of quail Schwann cells into chick embryos}

Quail SMP+ Schwann cells, immunopurified as described above, were used for constructing quail-chick chimeras. After overnight incubation in control medium, about $10^{3}$ cells were scraped off the culture dish and implanted into the mesenchyme of BA1 in E2-chick embryos (stage 1516 of Hamburger and Hamilton, 1951), using a fine-tipped glass micropipette. The hosts were further incubated and those surviving at $E 9$ $(n=2 / 6)$ were sacrificed and treated by standard histological procedures. After fixation, dehydration and paraffin embedding, sections of the host embryos were treated for antigen retrieval by microwave exposure (twice 
$5 \mathrm{~min}$, in $0.01 \mathrm{M}$ citrate buffer at $700 \mathrm{~W}$ ). Then, the sections were incubated overnight at $4^{\circ} \mathrm{C}$ with the following primary antibodies: antiquail QCPN Mab for detection of the grafted quail cells (mouse IgG1 hybridoma from DSHB), together with anti- $\alpha$ SMA (mouse lgG2a; Sigma) and HNK1 (mouse lgM), to identify perivascular myofibroblasts and PNS cells, respectively. The secondary antibodies (all from Southern Biotechnology Ass.) were peroxidase-conjugated anti-mouse IgG1, APconjugated anti-mouse IgM and AP-conjugated anti-mouse IgG2a. The immunostainings were colour-developed using diaminobenzidine (for QCPN) and different chromogenic AP substrates (Vector) (for $\alpha$ SMA and HNK1).

\section{Acknowledgements}

This work was supported by the Centre National de la Recherche Scientifique and grant from Institut National de la Santé et de la Recherche Médicale (No 4CS13H). We thank S. Gournet for the illustrations and $M$. Scaglia for bibliography. QCPN and anti-PO mouse hybridoma cells were supplied by D.H.S.B., developed by the University of lowa, lowa City, IA. We also thank P. J. Scotting and M. A. Nieto for generously providing chick Sox10 and Slug plasmids, respectively. C.R. is recipient of a doctoral fellowship from Fundaçao para Ciencia e Tecnologia, Portugal (SFRH/BD/990/2000).

\section{References}

ABO, T. and BALCH, C.M. (1981). A differentiation antigen of human NK and K cells identified by a monoclonal antibody (HNK-1). J Immunol 127: 1024-9.

BAROFFIO, A., DUPIN, E. and LE DOUARIN, N.M. (1988). Clone-forming ability and differentiation potential of migratory neural crest cells. ProcNat/Acad SciUSA 85: 5325-9.

BAROFFIO, A., DUPIN, E. and LE DOUARIN, N.M. (1991). Common precursors for neural and mesectodermal derivatives in the cephalic neural crest. Development 112: $301-5$

BATES, D., TAYLOR, G.I., MINICHIELLO, J., FARLIE, P., CICHOWITZ, A., WATSON, N., KLAGSBRUN, M., MAMLUK, R. and NEWGREEN, D.F. (2003). Neurovascular congruence results from a shared patterning mechanism that utilizes semaphorin3a and neuropilin-1. Dev Biol 255: 77-98.

BHATTACHARYYA, A., FRANK, E., RATNER, N. and BRACKENBURY, R. (1991). $P 0$ is an early marker of the Schwann cell lineage in chickens. Neuron 7: 831-44.

BIXBY, S., KRUGER, G.M., MOSHER, J.T., JOSEPH, N.M. and MORRISON, S.J. (2002). Cell-intrinsic differences between stem cells from different regions of the peripheral nervous system regulate the generation of neural diversity. Neuron 35: 643-56

BROCKES, J.P. and KUMAR, A. (2002). Plasticity and reprogramming of differentiated cells in amphibian regeneration. Nat Rev Mol Cell Biol 3: 566-74

CARMELIET, P. (2003). Blood vessels and nerves: Common signals, pathways and diseases. Nat Rev Genet 4: 710-20.

CHEN, S. and LECHLEIDER, R.J. (2004). Transforming growth factor-beta-induced differentiation of smooth muscle from a neural crest stem cell line. Circ Res 94: 1195-202.

CHENG, Y., CHEUNG, M., ABU-ELMAGD, M.M., ORME, A. and SCOTTING, P.J. (2000). Chick sox10, a transcription factor expressed in both early neural crest cells and central nervous system. Brain Res Dev Brain Res 121: 233-41.

CIMENT, G. and WESTON, J.A. (1985). Segregation of developmental abilities in neural-crest-derived cells: Identification of partially restricted intermediate cell types in the branchial arches of avian embryos. Dev Biol 111: 73-83.

CLOUTHIER, D.E., HOSODA, K., RICHARDSON, J.A., WILLIAMS, S.C., YANAGISAWA, H., KUWAKI, T., KUMADA, M., HAMMER, R.E. and YANAGISAWA, M. (1998). Cranial and cardiac neural crest defects in endothelina receptor-deficient mice. Development 125: 813-24.

COULY, G.F., COLTEY, P.M. and LE DOUARIN, N.M. (1993). The triple origin of skull in higher vertebrates: A study in quail-chick chimeras. Development 117:409-29.

DULAC, C., CAMERON-CURRY, P., ZILLER, C. and LE DOUARIN, N.M. (1988). A surface protein expressed by avian myelinating and nonmyelinating Schwann cells but not by satellite or enteric glial cells. Neuron 1:211-20.
DULAC, C. and LE DOUARIN, N.M. (1991). Phenotypic plasticity of Schwann cells and enteric glial cells in response to the microenvironment. Proc Nat/ Acad Sci USA 88: 6358-62.

DULAC, C., TROPAK, M.B., CAMERON-CURRY, P., ROSSIER, J., MARSHAK, D.R., RODER, J. and LE DOUARIN, N.M. (1992). Molecular characterization of the Schwann cell myelin protein, Smp: Structural similarities within the immunoglobulin superfamily. Neuron 8: 323-34.

DUPIN, E., BAROFFIO, A., DULAC, C., CAMERON-CURRY, P. and LE DOUARIN, N.M. (1990). Schwann-cell differentiation in clonal cultures of the neural crest, as evidenced by the anti-Schwann cell myelin protein monoclonal antibody. Proc Natl Acad Sci USA 87: 1119-23.

DUPIN, E., GLAVIEUX, C., VAIGOT, P. and LE DOUARIN, N.M. (2000). Endothelin 3 induces the reversion of melanocytes to glia through a neural crest-derived glial-melanocytic progenitor. Proc Nat/ Acad Sci USA 97: 7882-7.

DUPIN, E. and LE DOUARIN, N.M. (2003). Development of melanocyte precursors from the vertebrate neural crest. Oncogene 22: 3016-23.

DUPIN, E., REAL, C., GLAVIEUX-PARDANAUD, C., VAIGOT, P. and LE DOUARIN, N.M. (2003). Reversal of developmental restrictions in neural crest lineages: Transition from Schwann cells to glial-melanocytic precursors in vitro. ProcNat/ Acad Sci USA 100: 5229-33.

EGUCHI, G. and OKADA, T.S. (1973). Differentiation of lens tissue from the progeny of chick retinal pigment cells cultured in vitro: A demonstration of a switch of cell types in clonal cell culture. Proc Nat/ Acad Sci USA 70: 14959.

ETCHEVERS, H.C., COULY, G., VINCENT, C. and LE DOUARIN, N.M. (1999). Anterior cephalic neural crest is required for forebrain viability. Development 126: 3533-43.

ETCHEVERS, H.C., VINCENT, C., LE DOUARIN, N.M. and COULY, G.F. (2001). The cephalic neural crest provides pericytes and smooth muscle cells to all blood vessels of the face and forebrain. Development 128: 1059-68.

FAUQUET, M. and ZILLER, C. (1989). A monoclonal antibody directed against quail tyrosine hydroxylase: Description and use in immunocytochemical studies on differentiating neural crest cells. J Histochem Cytochem 37: 1197-205.

FAWCETT, J.W. and KEYNES, R.J. (1990). Peripheral nerve regeneration. Annu Rev Neurosci 13: 43-60.

HAGEDORN, L., SUTER, U. and SOMMER, L. (1999). P0 and PMP22 mark a multipotent neural crest-derived cell type that displays community effects in response to TGF-beta family factors. Development 126: 3781-94.

ITO, K. and SIEBER-BLUM, M. (1991). In vitro clonal analysis of quail cardiac neural crest development. Dev Biol 148: 95-106.

IWASHITA, T., KRUGER, G.M., PARDAL, R., KIEL, M.J. and MORRISON, S.J. (2003). Hirschsprung disease is linked to defects in neural crest stem cell function. Science 301: 972-6.

JACOBS-COHEN, R.J., WADE, P.R. and GERSHON, M.D. (2002). Suppression of the melanogenic potential of migrating neural crest-derived cells by the branchial arches. Anat Rec 268: 16-26.

JAIN, M.K., LAYNE, M.D., WATANABE, M., CHIN, M.T., FEINBERG, M.W. SIBINGA, N.E., HSIEH, C.M., YET, S.F., STEMPLE, D.L. and LEE, M.E. (1998) In vitro system for differentiating pluripotent neural crest cells into smooth muscle cells. J Biol Chem 273: 5993-6.

KEMPF, H., LINARES, C., CORVOL, P. and GASC, J.M. (1998). Pharmacological inactivation of the endothelin type $A$ receptor in the early chick embryo: $A$ model of mispatterning of the branchial arch derivatives. Development 125: 4931-41.

KIRBY, M.L. and WALDO, K.L. (1995). Neural crest and cardiovascular patterning. Circ Res 77: 211-5.

KRUGER, G.M., MOSHER, J.T., BIXBY, S., JOSEPH, N., IWASHITA, T. and MORRISON, S.J. (2002). Neural crest stem cells persist in the adult gut but undergo changes in self-renewal, neuronal subtype potential and factor responsiveness. Neuron 35: 657-69.

KUMAR, M.S. and OWENS, G.K. (2003). Combinatorial control of smooth musclespecific gene expression. Arterioscler Thromb Vasc Biol 23: 737-47.

KURIHARA, Y., KURIHARA, H., SUZUKI, H., KODAMA, T., MAEMURA, K., NAGAI, R., ODA, H., KUWAKI, T., CAO, W.H., KAMADA, N. et al. (1994). Elevated blood pressure and craniofacial abnormalities in mice deficient in endothelin-1. Nature 368: 703-10. 
LAHAV, R., DUPIN, E., LECOIN, L., GLAVIEUX, C., CHAMPEVAL, D., ZILLER, C. and LE DOUARIN, N.M. (1998). Endothelin 3 selectively promotes survival and proliferation of neural crest-derived glial and melanocytic precursors in vitro. Proc Natl Acad Sci USA 95: 14214-9.

LE DOUARIN, N. (1982). The neuralcrest. Cambridge University Press, Cambridge.

LE DOUARIN, N. and KALCHEIM, C. (1999). The neuralcrest. Cambridge University Press, Cambridge; New York.

LE DOUARIN, N.M. and DUPIN, E. (2003). Multipotentiality of the neural crest. Curr Opin Genet Dev 13: 529-36.

LE LIEVRE, C.S. and LE DOUARIN, N.M. (1975). Mesenchymal derivatives of the neural crest: Analysis of chimaeric quail and chick embryos. J Embryol Exp Morphol 34: 125-54.

MANN, K.M., RAY, J.L., MOON, E.S., SASS, K.M. and BENSON, M.R. (2004). Calcineurin initiates smooth muscle differentiation in neural crest stem cells. $J$ Cell Biol 165: 483-91.

MARIN, F. and NIETO, M.A. (2004). Expression of chicken slug and snail in mesenchymal components of the developing central nervous system. Dev Dyn 230: 144-8.

MASAKI, T. (2004). Historical review: Endothelin. Trends Pharmacol Sci 25: 219-24.

MCGANN, C.J., ODELBERG, S.J. and KEATING, M.T. (2001). Mammalian myotube dedifferentiation induced by newt regeneration extract. ProcNat/Acad Sci USA 98: 13699-704

MORRISON, S.J., WHITE, P.M., ZOCK, C. and ANDERSON, D.J. (1999). Prospective identification, isolation by flow cytometry and in vivo self-renewal of multipotent mammalian neural crest stem cells. Cell 96: 737-49.

MUKOUYAMA, Y.S., SHIN, D., BRITSCH, S., TANIGUCHI, M. and ANDERSON, D.J. (2002). Sensory nerves determine the pattern of arterial differentiation and blood vessel branching in the skin. Cell 109: 693-705.

NAKAMURA, H. and AYER-LE LIEVRE, C.S. (1982). Mesectodermal capabilities of the trunk neural crest of birds. J Embryol Exp Morphol 70: 1-18.

NATAF, V., MERCIER, P., ZILLER, C. and LE DOUARIN, N.M. (1993). Novel markers of melanocyte differentiation in the avian embryo. Exp Cell Res 207: 171-82.
NIETO, M.A., SARGENT, M.G., WILKINSON, D.G. and COOKE, J. (1994). Control of cell behavior during vertebrate development by slug, a zinc finger gene. Science 264: 835-9.

ODELBERG, S.J., KOLLHOFF, A. and KEATING, M.T. (2000). Dedifferentiation of mammalian myotubes induced by msx1. Cell 103: 1099-109.

OETTGEN, P. (2001). Transcriptional regulation of vascular development. Circ Res 89: $380-8$.

OKADA, T.S. (1991). Transdifferentiation: Flexibility in cel/ differentiation. Clarendon Press, Oxford.

OWENS, G.K. (1995). Regulation of differentiation of vascular smooth muscle cells. Physiol Rev 75: 487-517.

ROSSANT, J. and HOWARD, L. (2002). Signaling pathways in vascular development. Annu Rev Cell Dev Biol 18: 541-73.

SHAH, N.M., GROVES, A.K. and ANDERSON, D.J. (1996). Alternative neural crest cell fates are instructively promoted by TGFbeta superfamily members. Cel/ 85: 331-43.

SIEBER-BLUM, M. (1991). Role of the neurotrophic factors BDNF and NGF in the commitment of pluripotent neural crest cells. Neuron 6: 949-55.

STEMPLE, D.L. and ANDERSON, D.J. (1992). Isolation of a stem cell for neurons and glia from the mammalian neural crest. Cel/ 71: 973-85.

TRENTIN, A., GLAVIEUX-PARDANAUD, C., LE DOUARIN, N.M. and DUPIN, E. (2004). Self-renewal capacity is a widespread property of various types of neural crest precursor cells. Proc Nat/ Acad Sci USA 101: 4495-500.

TSONIS, P.A. (2004). Stem cells from differentiated cells. Mol Interv 4: 81-3.

TUCKER, G.C., AOYAMA, H., LIPINSKI, M., TURSZ, T. and THIERY, J.P. (1984). Identical reactivity of monoclonal antibodies HNK-1 and NC-1: Conservation in vertebrates on cells derived from the neural primordium and on some leukocytes. Cell Differ 14: 223-30.

YOUN, Y.H., FENG, J., TESSAROLLO, L., ITO, K. and SIEBER-BLUM, M. (2003). Neural crest stem cell and cardiac endothelium defects in the TrkC null mouse. Mol Cell Neurosci 24: 160-70. 